\title{
Insights from Crystal Size and Band Gap on the Catalytic Activity of Monoclinic $\mathrm{BiVO}_{4}$
}

\author{
Thalluri S. R. M., Martinez-Suarez C., Virga A., Russo N., and Saracco G.
}

\begin{abstract}
Monoclinic $\mathrm{BiVO}_{4}$ powders were synthesized from $\mathrm{Bi}\left(\mathrm{NO}_{3}\right)_{3} .5 \mathrm{H}_{2} \mathrm{O}$ and $\mathrm{NH}_{4} \mathrm{VO}_{3}$ in dilute $\mathrm{HNO}_{3}$ by homogenous co-precipitation followed by calcination at different temperatures ranging from 350 to $700^{\circ} \mathrm{C}$. The effects of increase in the calcination temperatures over the changes in the physicochemical parameters were evaluated by characterization techniques such as XRD, UV-Vis spectroscopy, Raman analysis and Field Emission Scanning Electron Microscopy (FE-SEM). The parameters responsible for the photochemical water oxidation were studied in detail and it was confirmed from our results that crystalline size and band gap of the $\mathrm{BiVO}_{4}$ powders are the main responsible for its activity. It is also confirmed from the changes in the intensities and shift in the peak position of Raman analysis, the effect of calcination temperatures over the variations such as lone pair distortions on $\mathrm{Bi}^{3+}$ and changes of $\mathrm{V}-\mathrm{O}$ bond length in the local structure of $\mathrm{BiVO}_{4}$.
\end{abstract}

Index Terms-Band gap, crystal size, monoclinic $\mathrm{BiVO}_{4}$, raman analysis.

\section{INTRODUCTION}

Development and application of cleaner energy systems play a crucial role towards sustainable development; in particular, increasing $\mathrm{CO}_{2}$ emissions, environmental impacts and socio-economic issues related with the production, distribution and use of energy sources, call for an urgent improvement of the current available technologies [1]- [3].

Solar energy being the most abundant energy source has been widely exploited for thermal and electrical power generation [1], [4]; however, due to a higher convenience of a means of chemical energy storage, such as $\mathrm{H}_{2}$, as compared to electricity, solar fuels have been regarded as one of the most promising technological concepts due to its potential higher efficiency and environmental suitability [5]-[7].

In this context, photocatalytic water splitting into $\mathrm{H}_{2}$ and $\mathrm{O}_{2}$ is a topic of increasing interest at present [3], [7]. In order to realize this, the first challenge to be addressed is the accomplishment of the water oxidation half-reaction $\left(2 \mathrm{H}_{2} \mathrm{O}\right.$ $\rightarrow \mathrm{O}_{2}+4 \mathrm{H}^{+}+4 \mathrm{e}^{-}$), considered as a limiting step since it involves a thermodynamically uphill reaction comprising the simultaneous transference of 4 electrons [2], [8]. Furthermore, development of a catalyst which can utilize whole electromagnetic spectrum is preferred in order to enhance overall water splitting efficiency of photocatalysts [9].

In order to carry out oxidation of water several photocatalysts have been developed and assessed in the last decades [2], [9]-[11] finding out that $\mathrm{BiVO}_{4}$ is one of the most active $\mathrm{O}_{2}$ evolution photocatalysts in the field of

Manuscript received July 2, 2013; revised September 1, 2013.

The authors are with the Politecnico di Torino, Piedmont, Italy (email: sitaramanjaneya.thalluri@polito.it). semiconductor particles and photoanodes [9], [12], due to i) a relatively low band gap of around $2.4 \mathrm{eV}$ for the monoclinic phase [13] enabling the more efficient use of visible light, and ii) an adequate position of the conduction and valance bands as compared to the potential of water oxidation [12]. In addition, $\mathrm{BiVO}_{4}$ is a non-toxic and relatively abundant material [12], [14].

It has been previously reported that among the three occurring phases of $\mathrm{BiVO}_{4}$, i.e. scheelite-tetragonal $(s-t)$, zircon-tetragonal $(z-t)$ and scheelite-monoclinic $(s-m)$, the latter is the only one that is highly active for $\mathrm{O}_{2}$ evolution under visible-light irradiation due to its particular crystal and electronic structure [13], [15]. However, currently, there is still an incomplete understanding of the physical properties in $\mathrm{BiVO}_{4}$ that lead to a high photocatalytic activity, as well as of the formation processes correlated with this phenomena.

Several synthesis methods have been utilized in order to prepare $\mathrm{BiVO}_{4}$ powders of high quality, predominantly solid-state, aqueous-based and hydrothermal methods [8], [12], [16]-[18]; among them, a simple solution-based preparation method under acidic conditions has been chosen and applied here, involving the calcination of obtained $\mathrm{BiVO}_{4}$ precipitates at different temperatures. From this, an in-depth analysis of some of the important physical parameters of as-obtained products allows for a coherent correlation with the different photocatalytic $\mathrm{O}_{2}$ evolution. The insights gained from this analysis contribute to the better understanding of the visible-light water oxidation mechanisms and ultimately will lead to the synthesis optimization of more efficient photocatalytic materials.

\section{EXPERIMENTAL DETAILS}

Samples of $\mathrm{BiVO}_{4}$ powders were synthesized by dissolving $5 \mathrm{mmol}$ of bismuth nitrate pentahydrate, $\mathrm{Bi}\left(\mathrm{NO}_{3}\right)_{3} \cdot 5 \mathrm{H}_{2} \mathrm{O}$ (Sigma Aldrich) in $100 \mathrm{~mL}$ of $1 \mathrm{M} \mathrm{HNO}_{3}$ until a clear solution was observed (ca. $30 \mathrm{~min}$.); later $5 \mathrm{mmol}$ of ammonium metavanadate, $\mathrm{NH}_{4} \mathrm{VO}_{3}$ (Sigma Aldrich) were added to the mixture, which was left for overnight stirring. Precipitate was collected by centrifugation, washed 3 times in distilled water and one time in ethanol, and finally dried at 80 ${ }^{\circ} \mathrm{C}$ overnight. Finally, the samples were calcined in air at different temperatures: $350{ }^{\circ} \mathrm{C}, 450{ }^{\circ} \mathrm{C}, 550{ }^{\circ} \mathrm{C}$ and $700{ }^{\circ} \mathrm{C}$ for 3 hours.

Samples were characterized by X-ray diffraction (XRD) using an X'Pert Phillips diffractometer equipped with $\mathrm{Cu} \mathrm{K \alpha}$ radiation $(\lambda=1.5418 \AA)$ at $40 \mathrm{kV}$ and $30 \mathrm{~mA}$. All the patters were recorded in the range of $5-60^{\circ}$ at a step size of $0.02^{\circ}$. Crystallite sizes of the samples were estimated by using Scherrer formula [19]: 


$$
D=\frac{K \lambda}{\beta \cos \theta}
$$

where $D$ is the approximated crystallite size, $\lambda$ is the wavelength of the X-ray radiation $(0.15418 \mathrm{~nm}) ; K$ is the shape factor $(0.9) ; \beta$ is the peak width at half-maximum height corrected for instrumental broadening; $2 \theta=30.6^{\circ}$. $\mathrm{UV}-\mathrm{Vis}$ diffuse reflectance spectra were recorded on a UV-Vis Varian's Cary 5000 spectrophotometer using a quartz cell suitable for powders measurements. The morphology of the samples was investigated by Field emission Scanning Electron Microscopy (FE-SEM) taken with a high-resolution FE-SEM instrument (LEO 1525). Raman spectra were obtained by means of a Renishaw inVia Reflex (Renishaw PLC, United Kingdom) micro-Raman spectrophotometer equipped with a cooled charge-coupled device camera. Samples were excited with an $\mathrm{Ar}-\mathrm{Kr}$ laser source $(648 \mathrm{~nm})$, providing a photon flux lower than 60 $\mathrm{W} / \mathrm{cm} 2$. The spectral resolution and integration time were 3 $\mathrm{cm}^{-1}$ and $30 \mathrm{~s}$, respectively. All the Raman spectra excited with the same wavelength directly compared in the following sections were recorded at similar conditions.

Photocatalytic $\mathrm{O}_{2}$ evolution of the samples was carried out from a silver nitrate $\mathrm{AgNO}_{3}(50 \mathrm{mM} ; 110 \mathrm{~mL})$ solution used as electron acceptor. In a typical test, ca. $100 \mathrm{mg}$ of overnight-outgassed $\mathrm{BiVO}_{4}$ powders were dispersed in the $\mathrm{AgNO}_{3}$ solution in a $200 \mathrm{~cm}^{3}$ Pyrex reactor cell equipped with an external cooling jacket to maintain a constant temperature. Ar gas was used as a carrier and fluxed in the reactor cell under dark conditions in order to evacuate the air inside, and a constant flow of $12 \mathrm{~mL} \mathrm{~min}^{-1}$ was kept during the test. The reactor cell was side-illuminated with a simulated solar light by using a plasma lamp (Solaronix model LIFI STA-40), whereas the irradiance of incident light was measured to be $100 \mathrm{~mW} \mathrm{~cm}{ }^{-2}$ using a photo-radiometer Delta Ohm model HD2101.1. Illumination was kept during one hour and the amount of evolved $\mathrm{O}_{2}$ was determined in the out-flowing gas using a gas chromatograph (Varian $490-\mu \mathrm{GC}$, Molsieve 5A column $10 \mathrm{~m}$, micro-TCD detector) until no traces of $\mathrm{O}_{2}$ were measured, and the cumulative $\mathrm{O}_{2}$ evolution over $1 \mathrm{~h}$ of illumination was estimated by the integration of the GC measurements over time.

\section{RESULTS AND DISCUSSION}

\section{A. Characterization and Photocatalytic Activity Evaluation}

The XRD patterns of $\mathrm{BiVO}_{4}$ samples calcined at different temperatures are shown in Fig. 1; all these samples exhibit the scheelite-monoclinic (s-m) phase as their diffraction peaks are in good agreement with the standard Joint Committee on Powder Diffraction Standards (JCPDS) card No. 14-0688 (space group: I2/a, a=5.195, b=11.701, c=5.092, $\beta=90.38^{\circ}$ ). Moreover, all the samples show the characteristic peak splitting diffractions at $2 \theta=18.5,35$ and $46^{\circ}$ [20]. Even though monoclinic phase was observed at every calcination temperature, splitting of the these characteristics peaks becomes more pronounced as the calcination temperature increases, which is most likely a sign of the increasing crystallinity degree of the (s-m) phase in $\mathrm{BiVO}_{4}$ samples [20], [21].

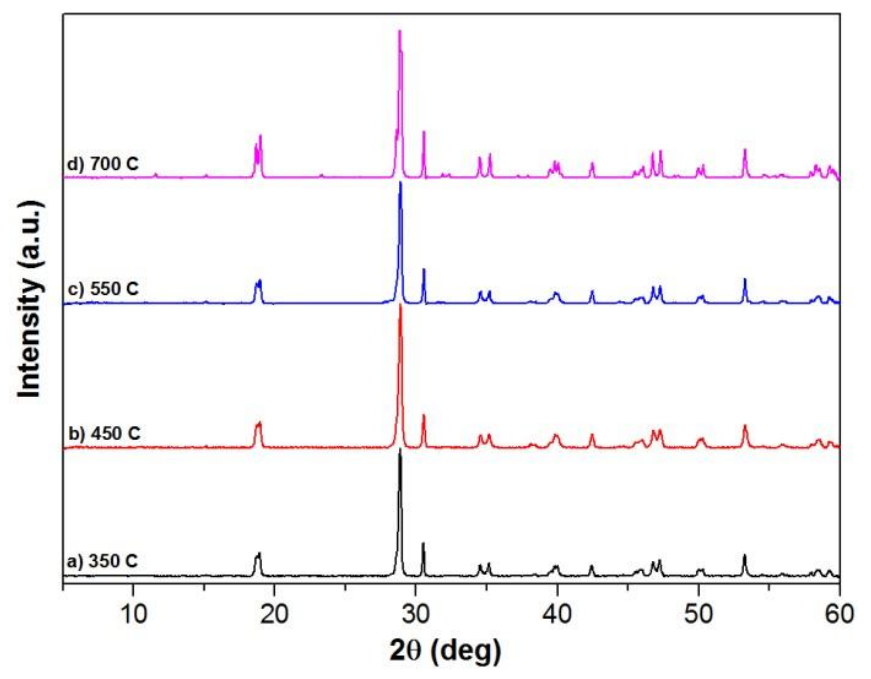

Fig. 1. XRD patterns of the $\mathrm{BiVO}_{4}$ samples synthesized at different calcination temperatures: a) $350{ }^{\circ} \mathrm{C}$; b) $450{ }^{\circ} \mathrm{C}$; c) $550{ }^{\circ} \mathrm{C}$; and d) $700{ }^{\circ} \mathrm{C}$

The FE-SEM images of $\mathrm{BiVO}_{4}$, powders are given in the Fig. 2. If we have a close look into the pictures significant differences can be observed among the different samples. The samples calcined at 350 and $450^{\circ} \mathrm{C}(\mathrm{a}-\mathrm{b})$ show crystals with well-defined surfaces and a low degree of agglomeration. The powder samples calcined at 550 and $700^{\circ} \mathrm{C}$ (c-d) showed a clear variation in morphology and degree of agglomeration of particles, probably due to increased sintering at higher calcination temperatures.

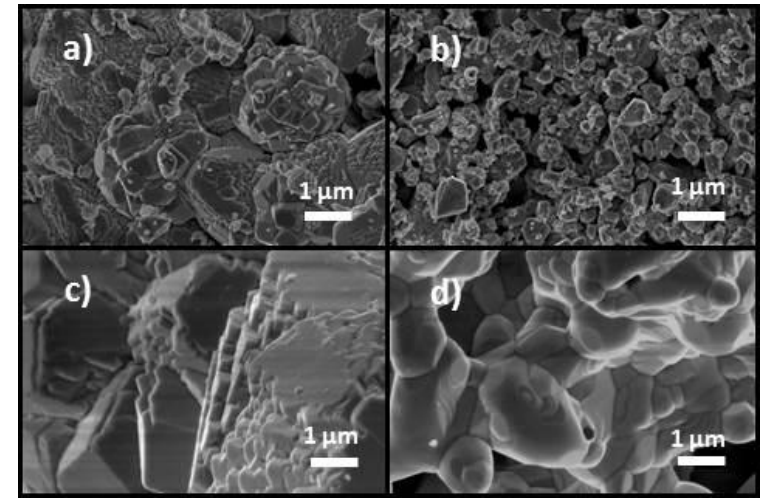

Fig. 2. FE-SEM images of $\mathrm{BiVO}_{4}$ samples synthesized at different calcination temperatures: a) $350^{\circ} \mathrm{C}$; b) $450^{\circ} \mathrm{C}$; c) $550^{\circ} \mathrm{C}$ and d) $700^{\circ} \mathrm{C}$.

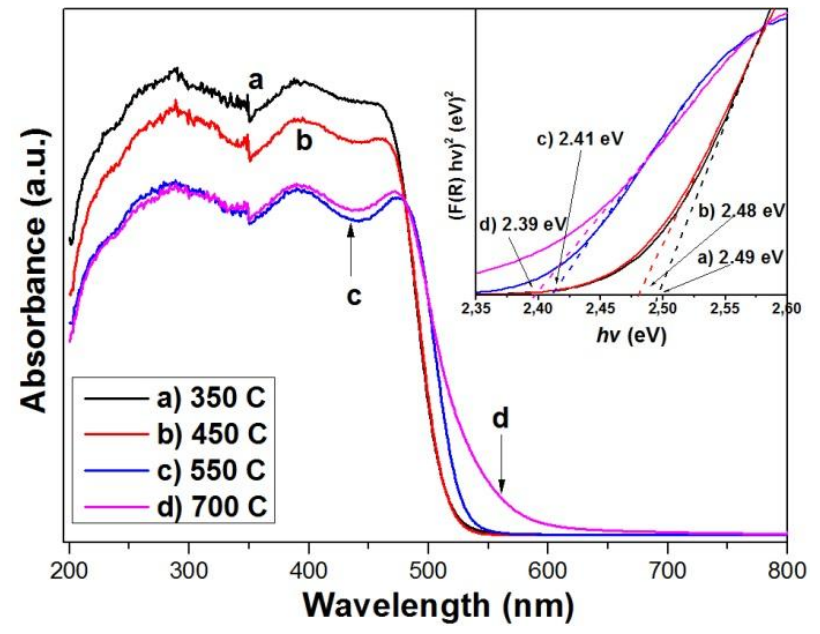

Fig. 3. UV-Vis diffuse reflectance spectra of $\mathrm{BiVO}_{4}$ powders synthesized at different calcination temperatures: a) $350{ }^{\circ} \mathrm{C}$; b) $450{ }^{\circ} \mathrm{C}$; c) $550{ }^{\circ} \mathrm{C}$; and d) $700{ }^{\circ} \mathrm{C}$ and inset with Tauc plots showing the effect of calcination temperature on the band gap energy shift. 
In order to calculate the electronic states of the semiconductor materials diffuse reflectance spectra (DRS) is used. The DRS of the $\mathrm{BiVO}_{4}$ samples calcined at different temperatures is shown in Fig. 1. All samples show absorption in the visible region of the electromagnetic spectrum. This gives us information about the monoclinic nature of the BiVO4 samples [13]. The changes in the absorption edges can be observed among the four BIVO4 samples. A red shift was observed among the samples with an increase in the calcination temperature. The band gaps were calculated using Tauc plot and are 2.49,2.48, 2.41 and $2.39 \mathrm{eV}$ for the samples calcined at $350,450,550,700^{\circ} \mathrm{C}$, respectively.

These variations in the samples are in turn responsible for the degree of delocalization of photogenerated electron and hole pairs [18].

Raman spectra of $\mathrm{BiVO}_{4}$ powders were excited by a red $(648 \mathrm{~nm})$ laser and corresponding spectra are shown in Fig. 4. Raman spectroscopy can provide structural information and is also a sensitive method for the investigation of the crystallization, local structure, and electronic properties of materials. Raman bands around 210, 324, 366, 640, 710, and $826 \mathrm{~cm}^{-1}$ were observed for all samples. These are the typical vibrational bands of $\mathrm{BiVO}_{4}$ [18], [20], [22]. The structural information of $\mathrm{BiVO}_{4}$ is given by the band centered at 210 $\mathrm{cm}^{-1}$. The asymmetric and symmetric formations of $\mathrm{VO}_{4}$ tetrahedron are given by the bands centered at 324 and 366 $\mathrm{cm}^{-1}$, respectively. The Raman band at $640 \mathrm{~cm}^{-1}$ can be assigned to the asymmetric stretching vibration of the shorter $\mathrm{V}-\mathrm{O}$ bond. The stretching modes of two vibrational modes of $\mathrm{V}-\mathrm{O}$ bonds are determined by the bands centered at 710 and $826 \mathrm{~cm}^{-1}$. These two bands provide valuable information about the structural variations among the powder samples calcined at different temperatures. It has been observed a positive shift in the vibrational mode of $\mathrm{V}-\mathrm{O}$, which varies from 825.30 to $827.52 \mathrm{~cm}^{-1}$. The shift follows a linear trend with the calcination temperature, such as, 825.30, 825.95, 826.62 and $827.59 \mathrm{~cm}^{-1}$ for $350,450,550$ and $700{ }^{\circ} \mathrm{C}$ respectively (Table I). This shift can be correlated to the variations in bond length of the $\mathrm{V}-\mathrm{O}$ which can be calculated by (2). The Raman stretching frequencies and the respective metal-oxygen bond lengths share an inverse relationship which describes that a higher stretching frequency will correspond to a lower metal-oxygen bond length. By utilizing the expression for bond length, [23] and [24]:

$$
v\left(\mathrm{~cm}^{-1}\right)=21349 \exp \left(-1.9176 R\left(A^{o}\right)\right)
$$

where $v$ is the stretching Raman frequency for $\mathrm{V}-\mathrm{O}$, it can be seen that the bond length varies from 1.6964 to $1.6950 \mathrm{~A}^{\circ}$ for 350 to $700{ }^{\circ} \mathrm{C}$ samples, respectively.

The synthesized $\mathrm{BiVO}_{4}$ samples were all investigated to determine their photocatalytic $\mathrm{O}_{2}$ evolution activity from $\mathrm{AgNO}_{3}$ solution as sacrificial reagent. The cumulative $\mathrm{O}_{2}$ evolution of the four samples synthesized at different calcination temperatures is shown in Fig. 5. It is observed that the photocatalytic activity increases with an increase in calcination temperature. The total $\mathrm{O}_{2}$ evolved after $1 \mathrm{~h}$ of illumination under simulated solar irradiation for the samples calcined at $350,450,550$ and $700^{\circ} \mathrm{C}$ was $2.6,5.6,17.9$ and $57.6 \mu \mathrm{mol} \mathrm{g}{ }^{-1}$ catalyst, respectively.

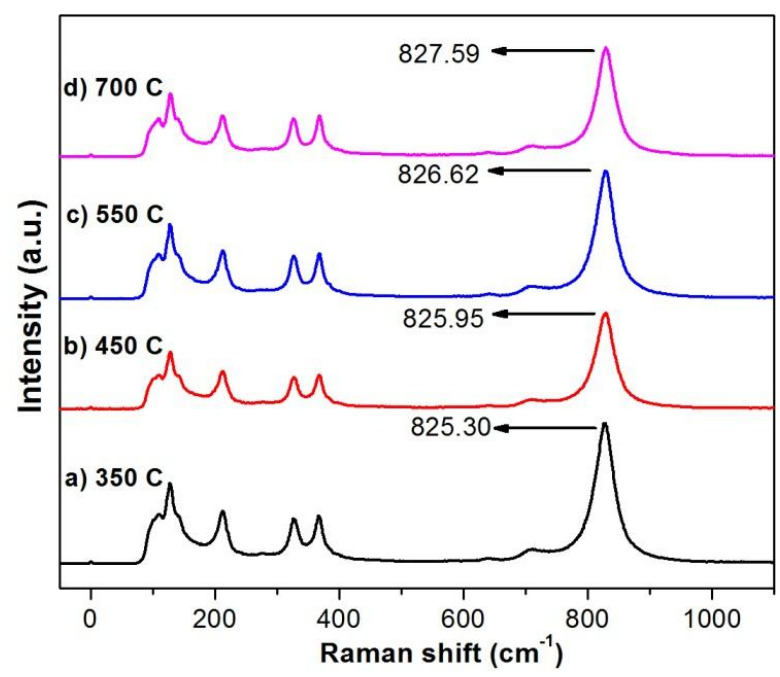

Fig. 4. Raman spectra of the $\mathrm{BiVO}_{4}$ samples synthesized at different calcination temperatures: a) $350{ }^{\circ} \mathrm{C}$; b) $450{ }^{\circ} \mathrm{C}$; c) $550{ }^{\circ} \mathrm{C}$; and d) $700{ }^{\circ} \mathrm{C}$ excited by a red-line laser $(648 \mathrm{~nm})$

\section{B. Correlation of $\mathrm{O}_{2}$ Evolution and Photophysical Parameters of $\mathrm{BiVO}_{4}$}

Herein as per our observations it has been noticed that certain parameters are mainly responsible for water oxidation of $\mathrm{BiVO}_{4}$ powders, such as crystallite sizes that can be acquired from XRD and band gap from UV-Vis spectroscopy. The crystal sizes were calculated according to (1).

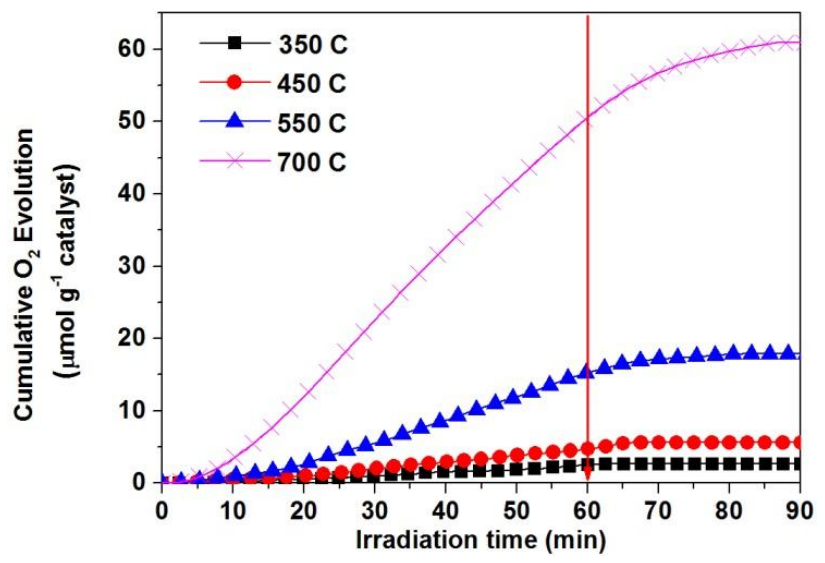

Fig. 5. Photocatalytic $\mathrm{O}_{2}$ evolution from $50 \mathrm{mM} \mathrm{AgNO}$ solution $(110 \mathrm{~mL})$ under simulated solar irradiation $\left(100 \mathrm{~mW} \mathrm{~cm}^{-2}\right)$ over $\mathrm{BiVO}_{4}$ powder catalyst $(100 \mathrm{mg})$ calcined at different temperatures

As the calcination temperature increases there is an increase in the crystallite size of the powder samples; moreover there is a good correlation of the increase in the crystalline size and enhancement of $\mathrm{O}_{2}$ evolution, as observed in table I. Even though all samples showed monoclinic phase as per XRD patterns analyzed above, there are differences among the intensities and half-widths of the peaks which describe little variations in the structural parameters of the powder samples. This can be elucidated from the UV-Vis spectra and Raman analysis. The differences in the intensities and peak position of the bands in the Raman spectra clearly demonstrate the variations in the local crystal structure among the powder samples, as the frequencies related to the $\mathrm{VO}_{4}$ tetrahedron and $\mathrm{V}-\mathrm{O}$ bonds are directly related to the interactive forces between $\mathrm{Bi}^{+3}$ and $\mathrm{V}^{5+}$ cations. It can be noticed from the relative intensities of the Raman spectra among the powder samples that $\mathrm{VO}_{4}{ }^{3-}$ tetrahedron with 
different $\mathrm{VO}_{4}$ space symmetries were formed. It can also be noticed that variations in one of the V-O bond length among the powder samples can be explained on the basis of packing of the structure. The stronger is the packing, shorter is V-O bond length and higher the photocatalytic activity. This can be directly correlated to the lone pair distortion around the bismuth cation as it has a negative effect to the bond length of the V-O. So, there is more distortion of lone pairs in powder samples calcined at $700^{\circ} \mathrm{C}$ rather than the samples calcined at $350^{\circ} \mathrm{C}$. This is an effect that is canceled when we characterize the sample with XRD as it is not sensitive enough to the slight changes in the bond lengths that have an inverse effect.

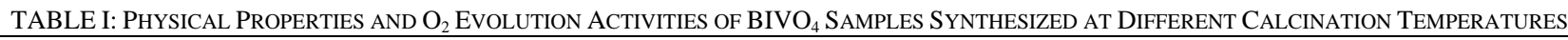

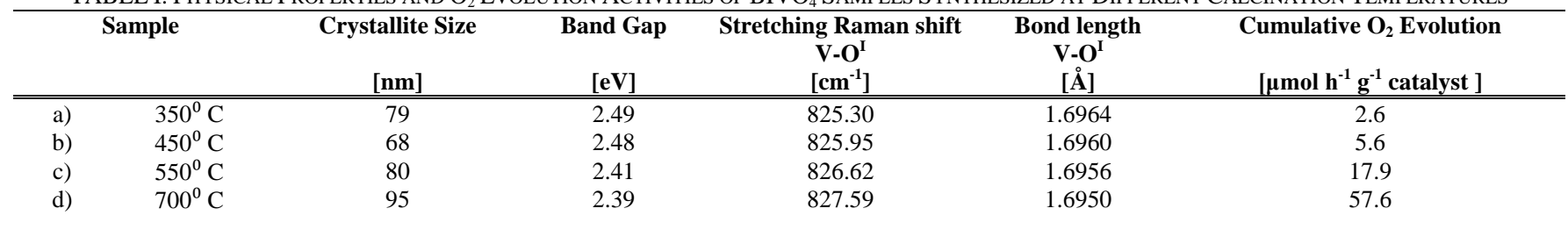

The band structure in scheelite-monoclinic $\mathrm{BiVO}_{4}$ is formed by the $\mathrm{Bi} 6 \mathrm{~s}, \mathrm{O} 2 \mathrm{p}$ and V3d orbitals; among them, valence band is formed by the hybrid of Bi6s and $\mathrm{O} 2 \mathrm{p}$ and conduction band by V3d [25]. There is a distinct variation observed in the electronic structure of the samples when the distortion of the $\mathrm{VO}_{4}{ }^{3-}$ tetrahedron occurs. This distortion is due to the lone pair electron of $\mathrm{Bi}^{3+}$ in the local structure of the $\mathrm{BiVO}_{4}$. There is a change in the extent of overlapping of $\mathrm{Bi} 6 \mathrm{~s}$ and $\mathrm{O} 2 \mathrm{p}$ with the distortion of $\mathrm{VO}_{4}{ }^{3-}$ tetrahedron. This overlapping is directly proportional to the degree of distortion which in turn helps in the mobility of photogenerated holes [18]. Thus it can be summarized from XRD, Raman and UV-Vis spectroscopy that increase in crystallinity of powder samples lead to an increase in the delocalization of the electron and hole pairs and a higher overlapping between the $\mathrm{Bi} 6 \mathrm{~s}$ and $\mathrm{O} 2 \mathrm{p}$ orbitals, which finally increases the $\mathrm{O}_{2}$ evolution of $\mathrm{BiVO}_{4}$.

\section{CONCLUSION}

In our study, it has been confirmed the importance of crystal-size and band gap in correlation with the photochemical water oxidation. The importance of Raman analysis in understanding the variations in a crystal structure is also explained in detail. Thus, keeping in consideration of crystal size to the band gap, one can improve the activity of the $\mathrm{BiVO}_{4}$ photocatalyst.

\section{ACKNOWLEDGMENT}

The authors would like to thank the European commission for the financial support for this work which is a part of the 7th Framework Programme NMP-2012 Project Eco2Co2 nr.309701.

\section{REFERENCES}

[1] OECD/IEA, World Energy Outlook 2011, Cedex, France: IEA Publications, 2011

[2] A. Kudo and Y. Miseki, "Heterogeneous photocatalyst materials for water splitting," Chem. Soc. Rev., vol. 38, no. 1, pp. 253-278, 2009.

[3] N. S. Lewis and D. G. Nocera, "Powering the planet: Chemical challenges in solar energy utilization," Proc. Natl. Acad. Sci. U. S. A., vol. 103 , no. 43, pp. 15729-15735, Oct. 2006.

[4] P. Moriarty and D. Honnery, "What is the global potential for renewable energy?" Renew. Sustain. Energy Rev., vol. 16, no. 1, pp. 244-252, Jan. 2012.

[5] J. Turner, G. Sverdrup, M. K. Mann, P.-C. Maness, B. Kroposki, M. Ghirardi, R. J. Evans, and D. Blake, "Renewable hydrogen production," Int. J. Energy Res., vol. 32, no. 5, pp. 379-407, 2008.
[6] C. Ampelli, G. Centi, R. Passalacqua, and S. Perathoner, "Synthesis of solar fuels by a novel photoelectrocatalytic approach," Energy Environ. Sci., vol. 3, no. 3, pp. 292-301, 2010.

[7] J. Barber, "Photosynthetic energy conversion: natural and artificial," Chem. Soc. Rev., vol. 38, no. 1, pp. 185-196, 2009.

[8] D. Wang, H. Jiang, X. Zong, Q. Xu, Y. Ma, G. Li, and C. Li, "Crystal Facet Dependence of Water Oxidation on BiVO4 Sheets under Visible Light Irradiation," Chem. - Eur. J., vol. 17, no. 4, pp. 1275-1282, 2011.

[9] R. Abe, "Recent progress on photocatalytic and photoelectrochemical water splitting under visible light irradiation," J. Photochem. Photobiol, C-Photochem, Rev., vol. 11, no. 4, pp. 179-209, Dec. 2010.

[10] A. Fujishima and K. Honda, "Electrochemical photolysis of water at a semiconductor electrode," Nature, vol. 238, no. 5358, pp. 37, 1972.

[11] S. Bensaid, G. Centi, E. Garrone, S. Perathoner, and G. Saracco, "Towards Artificial Leaves for Solar Hydrogen and Fuels from Carbon Dioxide," Chemsuschem, vol. 5, no. 3, pp. 500-521, 2012.

[12] Y. Park, K. J. McDonald, and K.-S. Choi, "Progress in bismuth vanadate photoanodes for use in solar water oxidation," Chem. Soc. Rev., vol. 42, no. 6, pp. 2321-2337, 2013.

[13] A. Kudo, K. Omori, and H. Kato, "A novel aqueous process for preparation of crystal form-controlled and highly crystalline BiVO4 powder from layered vanadates at room temperature and its photocatalytic and photophysical properties," J. Am. Chem. Soc., vol. 121, no. 49, pp. 11459-11467, Dec. 1999.

[14] M. Gotić, S. Musić, M. Ivanda, M. Šoufek, and S. Popović, "Synthesis and characterisation of bismuth(III) vanadate," Mol. Spectrosc. Mol. Struct. 2004 Collect. Pap. Present. Xxviith Eur. Congr. Mol. Spectrosc. Krakow Pol. Sept. 5-10 2004, vol. 744-747, pp. 535-540, Jun. 2005.

[15] Z. Zhao, Z. Li, and Z. Zou, "Electronic structure and optical properties of monoclinic clinobisvanite BivO4," Phys. Chem. Chem. Phys., vol. 13, no. 10, pp. 4746-4753, 2011.

[16] A. Kudo, K. Ueda, H. Kato, and I. Mikami, "Photocatalytic O2 evolution under visible light irradiation on BiVO4 in aqueous AgNO3 solution," Catal. Lett., vol. 53, no. 3-4, pp. 229-230, Aug. 1998.

[17] S. Tokunaga, H. Kato, and A. Kudo, "Selective Preparation of Monoclinic and Tetragonal BiVO4 with Scheelite Structure and Their Photocatalytic Properties," Chem. Mater., vol. 13, no. 12, pp. 4624-4628, Nov. 2001.

[18] J. Yu and A. Kudo, "Effects of structural variation on the photocatalytic performance of hydrothermally synthesized BiVO4," Adv. Funct. Mater., vol. 16, no. 16, pp. 2163-2169, Oct. 2006.

[19] J. Langford and A. Wilson, "Scherrer after 60years survey and some new results in determination," J. Appl. Crystallogr., vol. 11, no. APR, pp. 102-113, 1978

[20] Y. K. Kho, W. Y. Teoh, A. Iwase, L. Maedler, A. Kudo, and R. Amarl, "Flame Preparation of Visible-Light-Responsive BiVO4 Oxygen Evolution Photocatalysts with Subsequent Activation via Aqueous Route," Acs Appl. Mater. Interfaces, vol. 3, no. 6, pp. 1997-2004, Jun. 2011.

[21] D. Ke, T. Peng, L. Ma, P. Cai, and P. Jiang, "Photocatalytic water splitting for $\mathrm{O}_{2}$ production under visible-light irradiation on BiVO4 nanoparticles in different sacrificial reagent solutions," Appl. Catal. Gen., vol. 350, no. 1, pp. 111-117, Nov. 2008.

[22] A. Galembeck and O. L. Alves, "BiVO ${ }_{4}$ thin film preparation by metalorganic decomposition," Thin Solid Films, vol. 365, no. 1, pp. 90-93, Apr. 2000.

[23] I. Brown and K. Wu, "Empirical parameters for calculating cation/oxygen bond valences," Acta Crystallogr. Sect. B-Struct. Sci., vol. 32, no. JUL15, pp. 1957-1959, 1976. 
[24] F. Hardcastle and I. Wachs, "Determination of vanadium oxygen bond distances and bond orders by Raman spectroscopy," J. Phys. Chem. vol. 95, no. 13, pp. 5031-5041, Jun. 1991

[25] A. Walsh, Y. Yan, M. N. Huda, M. M. Al-Jassim, and S.-H. Wei, "Band Edge Electronic Structure of BiVO4: Elucidating the Role of the Bi s and V d Orbitals," Chem. Mater., vol. 21, no. 3, pp. 547-551, Feb. 2009.

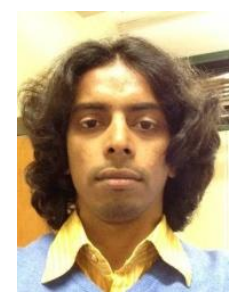

Sitaramanjaneya Mouli Thalluri is a native of India, he was born in Andhra Pradesh on 2 July 1984. He obtained his Bachelor's in Biotechnology from Jawaharlal Nehru Technological University (JNTU), India on 2008. He obtained his Masters in Nanotechnology from one of the prestigious institutes, Indian Institute of Technology Roorkee on 2010. He started his carrier in chemical engineering as a Doctorate scholar form Poletecnico di Torino, Italy since 2012 January.
He did his summer internship from Institute of Intelligent Machines, Hefei, China for a period of three months. He obtained fellowship from Chinese Academy of Sciences for the period of stay in China. He was also an M.H.R.D fellowship awarder for Masters at IIT Roorkee. He worked as a research assistant in Poletecnico di torino from July 2011 to December 2011. At present his doctoral research is awarded by Poletecnico di Torino.

Mr. Mouli obtained Merit award from St. Martins Engineering College affiliated to JNTU on 2008 for obtaining All India Rank, "92" in one of the prestigious national exam, Graduate aptitude test of Engineering (GATE 2008) for the entrance into IIT's in India,. He is greatly motivated to work in the field of Photocatalysis. His work in the field of photo-voltaics an sensors had been reported in Chemical Communications and Journal of Material Research. 